\title{
Regional reductions of gray matter volume in familial dyslexia
}

\author{
S.M. Brambati, BS; C. Termine, MD; M. Ruffino, BS; G. Stella, PhD; F. Fazio, MD; S.F. Cappa, MD; and \\ D. Perani, MD
}

\begin{abstract}
An in vivo anatomic study of gray matter volume was performed in a group of familial dyslexic individuals, using an optimized method of voxel-based morphometry. Focal abnormalities in gray matter volume were observed bilaterally in the planum temporale, inferior temporal cortex, and cerebellar nuclei, suggesting that the underlying anatomic abnormalities may be responsible for defective written language acquisition in these subjects.
\end{abstract}

NEUROLOGY 2004;63:742-745

There is increasing evidence for a genetic basis of dyslexia. Although the condition occurs frequently in members of the same family, neuropsychological profiles are highly variable among dyslexic individuals belonging to the same family and at different developmental stages. ${ }^{1}$

The presence and location of structural brain anomalies in dyslexia are controversial. Postmortem studies have shown multiple cortical abnormalities in dyslexic individuals' brains. ${ }^{1}$ In vivo MRI volumetric studies that have compared the size of brain structures of interest between dyslexic and control subjects have shown structural abnormalities involving temporal regions such as the planum temporale, the insula, and the cerebellum. However, there is lack of consistency among studies. Several methodologic factors may account for this discrepancy. In the first place, some studies are based on the a priori positioning of large regions of interest in each subject's brain (often the entire hemisphere or a lobe), without segmenting gray (GM) from white (WM) matter in the calculation of the volume of interest. Furthermore, the comparison between dyslexic and control subjects was often based on absolute volumetric regional differences, without taking into account important sources of variability such as wholebrain volume, age of the subjects, or differences in brain shape..$^{1-4}$

Voxel-based morphometry (VBM) is a useful tool to overcome these methodologic limitations. VBM is not biased to one particular structure but is a wholebrain technique for the detection of GM/WM tissue volume or density differences. In the case of volume, the regional size of GM or WM is measured and tested, whereas in the case of density, the measurement refers to the relative amount of a particular tissue in relation to other tissue types. The recent development of an optimized method of $\mathrm{VBM}^{5}$ has further improved the reliability and the objectivity of this technique. A previous VBM study in sporadic dyslexia found decreases in GM density, most notably in the left temporal lobe and bilaterally in the temporo-parieto-occipital juncture, but also in the frontal lobe, caudate, thalamus, and cerebellum. ${ }^{6}$

We sought to assess focal GM volumetric differences between familial dyslexics and normal readers that cannot be explained by differences in age or global amount of GM. On the basis of previous functional ${ }^{1,8,9}$ and anatomic ${ }^{1-4}$ findings, we expected to find GM reductions in brain areas associated with reading.

Methods. We recruited 10 dyslexic subjects ( 5 females, 5 males; age range 13 to 57 years, mean 31.6 years) belonging to four different families characterized by the presence of a proband with persistent, severe developmental dyslexia (according to International Classification of Diseases [10th ed.] criteria) and at least one first-degree relative with either clinically evident or compensated dyslexia. Compensated dyslexic subjects were characterized by a positive history of reading problems. Although they obtained normal scores on reading tests, they had difficulties and discomfort in reading and showed, as is often the case in dyslexia, associated impairments in meta-phonologic skills and in short-term memory (table 1).

The control group was composed of 11 non-reading-impaired subjects ( 6 females, 5 males; age range 14 to 55 years, mean 27.4 years). All participants were right handed and had no history of neurologic or psychiatric disorders. All subjects were administered an extensive battery of neuropsychological tests to delineate the cognitive phenotype.

T1-weighted volumetric spoiled gradient echo MRI scans were acquired with a 1.5 T GE Signal Horizon System (GE, Milwaukee, WI) using the following parameters: number of slices $=124$, slice thickness $=1.5 \mathrm{~mm}$, repetition time $=14.4$ milliseconds, echo time $=5.5$ milliseconds, inversion time $=700$ milliseconds.

Anatomic images including GM, WM, and CSF were created from the acquired brain volumes of the participants to provide a final template appropriate to our population sample.

From the Vita-Salute San Raffaele University (Drs. Cappa and Perani, S.M. Brambati and M. Ruffino), IBFM (Drs. Cappa, Perani, and Fazio), CNR, Segrate Milan, and University of Milano-Bicocca (Dr. Fazio), Milan, Child Neuropsychiatry Unit (Dr. Termine), University of Insubria, Varese, and Psychology Institute (Dr. Stella), University of Urbino, Italy.

Supported by A.I.D. ONLUS (Associazione Italiana Dislessia) and by the Vth European Program for the project "Connectivity in Language Rehabilitation" in Europe (LSDE).

Received October 31, 2003. Accepted in final form March 31, 2004.

Address correspondence and reprint requests to Dr. D. Perani, Vita-Salute H San Raffaele University, Via Olgettina 60, 20132 Milano, Italy; e-mail: daniela.perani@hsr.it 
Table 1 Performance of dyslexic and control subjects in neuropsychological assessment

\begin{tabular}{|c|c|c|c|c|c|c|c|c|c|c|c|c|}
\hline \multicolumn{4}{|l|}{ Intelligence } & \multicolumn{3}{|c|}{ Reading tests } & \multicolumn{3}{|c|}{ Short-term memory } & \multicolumn{2}{|c|}{ Metaphonologic tests } & \multirow[b]{2}{*}{$\begin{array}{c}\text { Token } \\
\text { Test }\end{array}$} \\
\hline WAIS-R/WISC-R & & & $\begin{array}{c}\text { Raven's } \\
\text { Progressive } \\
\text { Matrices }\end{array}$ & \multirow[t]{2}{*}{$\begin{array}{l}\text { Word } \\
\text { reading }\end{array}$} & $\begin{array}{l}\text { Non word } \\
\text { reading }\end{array}$ & $\begin{array}{c}\text { Short story } \\
\text { reading }\end{array}$ & \multirow[t]{2}{*}{ Digit } & \multicolumn{2}{|c|}{ Words Visuospatial } & \multirow[t]{2}{*}{ Fusion } & \multirow[t]{2}{*}{ Segmentation } & \\
\hline VIQ & PIQ & $\begin{array}{c}\text { Total } \\
\text { IQ }\end{array}$ & $Z$ score & & $Z$ scores & & & Sco & res & & & Scores \\
\hline \multicolumn{13}{|l|}{ Family 1} \\
\hline 112 & 120 & 119 & +0.68 & $-6.49 *$ & $-6.97 *$ & $-11.36^{*}$ & 2 & 4 & 4 & $0 / 26$ & $1 / 26^{*}$ & 2 \\
\hline 66 & 90 & 74 & +0.68 & $-12.29 *$ & $-9.63^{*}$ & $-13.46^{*}$ & 2 & 2 & 3 & $15 / 26^{*}$ & $26 / 26^{*}$ & 2 \\
\hline \multicolumn{13}{|l|}{ Family 2} \\
\hline 122 & 106 & 116 & +0.68 & -1.57 & $-2.04 *$ & $-2.06^{*}$ & 4 & 3 & 4 & $0 / 26$ & $6 / 26^{*}$ & 4 \\
\hline 104 & 110 & 114 & +1.65 & +0.60 & -0.48 & +1.36 & 4 & $1^{*}$ & 4 & $16 / 26^{*}$ & $3 / 26^{*}$ & 2 \\
\hline \multicolumn{13}{|l|}{ Family 3} \\
\hline 106 & 95 & 101 & +0.68 & $-4.35^{*}$ & $-3.84^{*}$ & $-6.43^{*}$ & 3 & 3 & $1^{*}$ & $6 / 26^{*}$ & $9 / 26^{*}$ & 3 \\
\hline 113 & 115 & 114 & +1.65 & -1.34 & -0.71 & +0.83 & 4 & 3 & 4 & $2 / 26^{*}$ & $1 / 26^{*}$ & $0 *$ \\
\hline 112 & 110 & 112 & +1.65 & -0.5 & -1.45 & +1.18 & 4 & 4 & 4 & $1 / 26^{*}$ & $2 / 26^{*}$ & 4 \\
\hline 106 & 116 & 111 & +1.65 & -0.89 & -0.73 & -0.5 & $1^{*}$ & $1^{*}$ & $1^{*}$ & $8 / 26^{*}$ & $0 / 26$ & 3 \\
\hline \multicolumn{13}{|l|}{ Family 4} \\
\hline 105 & 106 & 106 & +0.68 & $-3.08^{*}$ & $-2.62 *$ & $-3.6^{*}$ & 4 & 4 & 4 & $1 / 26^{*}$ & $1 / 26^{*}$ & 4 \\
\hline 107 & 100 & 104 & +0.68 & +0.52 & +0.41 & +5 & 4 & 4 & 4 & $22 / 26^{*}$ & $21 / 26^{*}$ & 2 \\
\hline $\begin{array}{l}\text { Control group } \\
\text { (11 subjects), } \\
\text { mean score }\end{array}$ & & & +1.65 & +1.09 & +1.26 & +6.3 & 4 & 4 & 4 & $0 / 26$ & $0 / 26$ & 4 \\
\hline
\end{tabular}

The scores in the control group are given as means of the results. Results of short-term memory tests and Token Test are scored in a range of 0 (pathologic performance) to 4 (highest score), according to available norms.

* Insufficient performance in the test.

WAIS-R = Wechsler Adult Intelligence Scale-Revised; WISC-R = Wechsler Intelligence Scale for Children-Revised; VIQ = Verbal IQ; $\mathrm{PIQ}=$ Performance IQ.

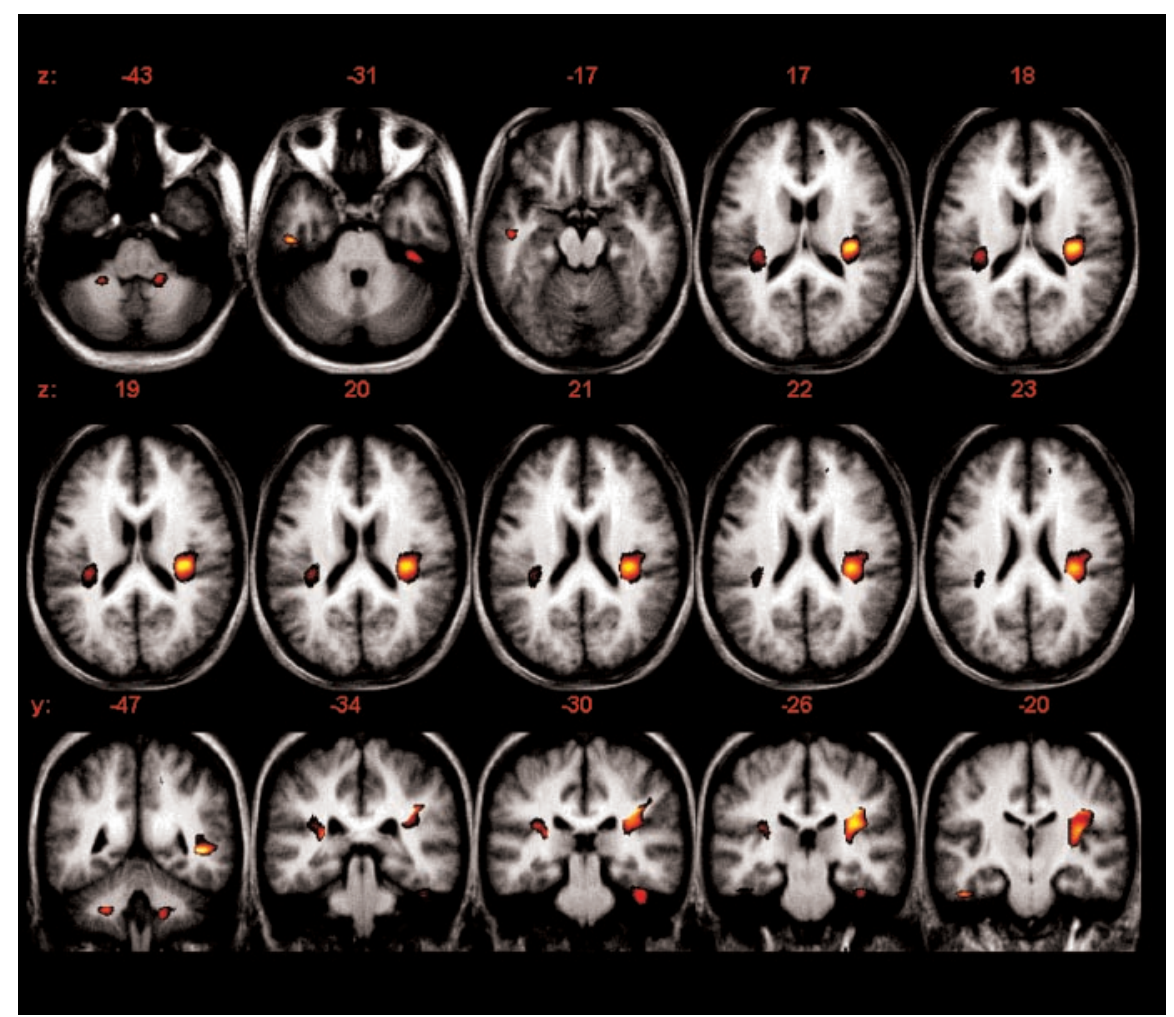

Figure. Maps of significant voxels representing regions of reduction in gray matter volume in familial dyslexic subjects superimposed on the mean dyslexics' anatomic MRI. The y and $\mathrm{z}$ values indicate the position of coronal and axial slices in the Talairach stereotaxic space. 
Table 2 Location of regional reduction of GM volume in group of familial dyslexics compared with control group

\begin{tabular}{lrrrr}
\hline Regional GM reduction & \multicolumn{1}{c}{ x } & \multicolumn{1}{c}{$z$} & \multicolumn{1}{c}{$Z$ score } \\
\hline Left planum temporale & -27 & -30 & 13 & 3,01 \\
Right planum temporale & 36 & -21 & 18 & 3,33 \\
Left fusiform gyrus, BA 37 & -47 & -19 & -25 & 3,18 \\
Right fusiform gyrus, BA 37 & 38 & -29 & -25 & 2,80 \\
Left inferior temporal gyrus, BA 20/21 & -48 & -14 & -14 & 2,80 \\
Left superior temporal gyrus, BA 22 & -41 & -55 & 14 & 2,88 \\
Right middle temporal gyrus, BA 21 & 43 & -45 & -31 & 3,41 \\
Left cerebellar nuclei & -22 & -46 & -34 \\
Right cerebellar nuclei & 16 & -45 & 282 \\
\hline
\end{tabular}

$p<0.05$ corrected for small brain volume, minimum cluster size $=25$ voxels, voxel size $=1 \times 1 \times 1 \mathrm{~mm} . x, y$, and $z$ values localize the areas of gray matter (GM) reduction according to the Talairach stereotactic coordinates. $k=$ cluster extent expressed in number of voxels; $\mathrm{BA}=$ Brodmann area.

Subsequently, we followed the procedures of the optimized VBM method. ${ }^{5}$ The first step of the analysis consists of the segmentation of the MR images in GM, WM, and CSF, removing nonbrain tissue (skull, scalp tissue, etc.). The segmented images were normalized to the customized templates, and then the normalization parameters identified for the segmented images were applied to the initial anatomic volume. Next, the normalized anatomic images were partitioned into GM, WM, and CSF and the nonbrain voxels removed. Jacobian modulation was applied to GM normalized segments to restore the original absolute volume of GM altered by the normalization process. Each optimally normalized, segmented, and modulated image was smoothed with a $12-\mathrm{mm}$ full width at half-maximum kernel.

All the image-processing procedures were performed using SPM2 (Wellcome Department of Cognitive Neurology, London, UK). To detect regional loss of GM in dyslexic subjects, which was unexplained by the age of the subjects and by global differences in total amount of GM, we introduced the values of age and total amount of GM for each subject as confounding covariates in an analysis of covariance. The critical threshold for analysis was $\mathrm{p}<$ 0.05 corrected for small brain volume.

Results. We observed significant regional reductions of GM volume in the group of familial dyslexic subjects in comparison with controls (figure). Regional GM abnormalities were located bilaterally in the planum temporale, inferior temporal cortex, and cerebellar nuclei, in the left superior and inferior temporal gyrus, and in the right middle temporal gyrus (table 2).

Discussion. We found localized GM volume reductions in critical functional components of the posterior reading network in familial dyslexic subjects. Psycholinguistic models describe two main stages in reading development. In novel readers, grapheme-tophoneme conversion mechanisms play a central role in the decoding of written language. On the other hand, in expert readers, the recognition of the abstract orthographic representation of familial words is crucial for the rapid access to the meaning and phonologic representations. Parieto-occipital regions play an important role in the first stage of reading acquisition, allowing the novel readers to perform a phonologic analysis of the words. On the other hand, inferotemporal regions are related to whole-word recognition and are recruited by expert readers in later stages of acquisition. ${ }^{7}$ Also, the cerebellum has been suggested to play a key role in reading, both at the peripheral (eye movements) and at the central level of written language processing. ${ }^{8}$

The evidence from functional neuroimaging studies is consistent with our findings of GM volume reductions located in the critical regions of the reading network. Previous PET and fMRI studies in dyslexic subjects engaged in reading or in phonologic tasks have revealed an anomalous pattern of activation in the left parietotemporal and inferotemporal regions as well as in the cerebellum, all components of the neural system dedicated to reading. This set of regions is less active in dyslexic than normal control subjects. ${ }^{1,8,9}$ It is noteworthy that a magnetic source imaging study has suggested that successful intensive remedial training results in the normalization of the activation profile in the posterior portion of the left superotemporal gyrus, ${ }^{10}$ that is, a region that we found affected in our study. The consistency between the current structural data and functional imaging results supports the reliability of the technique used in this study.

Further studies are required to generalize the current findings to sporadic cases of dyslexia. In addition, as the contribution of familial differences in the volume of GM, independent of the presence of dyslexia, cannot be ruled out, the specificity of the current anatomic findings for familial dyslexia needs studies within individual families.

\section{Acknowledgment}

The authors thank Massimo Danna, M. Eng, for help with MRI acquisition.

\section{References}

1. Habib M. The neurological basis of developmental dyslexia: an overview and working hypothesis. Brain 2000;123:2373-2399.

2. Pennington BF, Filipek PA, Lefly D, et al. Brain morphometry in reading-disabled twins. Neurology 1999;53:723-729.

3. Eliez S, Rumsey JM, Geidd JN, Schmitt JE, Patwardhan Aj, Reiss AL. Morphological alteration of temporal lobe gray matter in dyslexia: an MRI study. J Child Psychol Psychiatry 2000;41:637-644. 
4. Eckert MA, Leonard CM, Richards TL, et al. Anatomical correlates of dyslexia: frontal and cerebellar findings. Brain 2003;126:482-494.

5. Good CD, Johnsrude IS, Ashburner J, Henson RN, Friston KJ, Frackowiak RS. A voxel-based morphometric study of ageing in 465 normal adult human brains. Neuroimage 2001;14:21-36.

6. Brown WE, Eliez S, Menon V, Rumsey JM, White CD, Reiss AL. Preliminary evidence of widespread morphological variations of the brain in dyslexia. Neurology 2001;56:781-783.

7. Turkeltaub PE, Gareau L, Flowers DL, Zeffiro TA, Eden GF. Develop-- ment of neural mechanisms for reading. Nat Neurosci 2003;6:767-773.

8. Brunswick N, McCrory E, Price CJ, Frith CD, Frith U. Explicit and implicit processing of words and pseudowords by adult developmental dyslexics: a search for Wernicke's Wortschatz? Brain 1999;122:1901-1917.

9. Paulesu E, Démonet JF, Fazio F, et al. Dyslexia: cultural diversity and biological unity. Science 2001;291:2165-2167.

10. Simos PG, Fletcher JM, Bergman E, et al. Dyslexia-specific brain activation profile becomes normal following successful remedial training. Neurology 2002;58:1203-1213.

\section{ALERT: NEUROLOGY NOW USING ONLINE PEER REVIEW AND MANUSCRIPT SUBMISSION SYSTEM}

Neurology is now using an online peer review and manuscript submission system called Bench $>$ Press.

Authors should upload all original submissions via the Neurology website (www.submit.neurology.org). The Instructions to Authors detail the submission process and adjusted specifications. 


\section{Neurology}

\section{Regional reductions of gray matter volume in familial dyslexia}

S. M. Brambati, C. Termine, M. Ruffino, et al.

Neurology 2004;63;742-745

DOI 10.1212/01.WNL.0000134673.95020.EE

This information is current as of August 23, 2004

\section{Updated Information \& Services}

References

Citations

Subspecialty Collections

Permissions \& Licensing

Reprints including high resolution figures, can be found at: http://www.neurology.org/content/63/4/742.full.html

This article cites 10 articles, 7 of which you can access for free at: http://www.neurology.org/content/63/4/742.full.html\#\#ref-list-1

This article has been cited by 4 HighWire-hosted articles: http://www.neurology.org/content/63/4/742.full.html\#\#otherarticles

This article, along with others on similar topics, appears in the following collection(s):

\section{Dyslexia}

http://www.neurology.org//cgi/collection/dyslexia

MRI

http://www.neurology.org//cgi/collection/mri

Volumetric MRI

http://www.neurology.org//cgi/collection/volumetric_mri

Information about reproducing this article in parts (figures,tables) or in its entirety can be found online at:

http://www.neurology.org/misc/about.xhtml\#permissions

Information about ordering reprints can be found online: http://www.neurology.org/misc/addir.xhtml\#reprintsus

Neurology ${ }^{\circledR}$ is the official journal of the American Academy of Neurology. Published continuously since 1951, it is now a weekly with 48 issues per year. Copyright . All rights reserved. Print ISSN: 0028-3878. Online ISSN: 1526-632X.

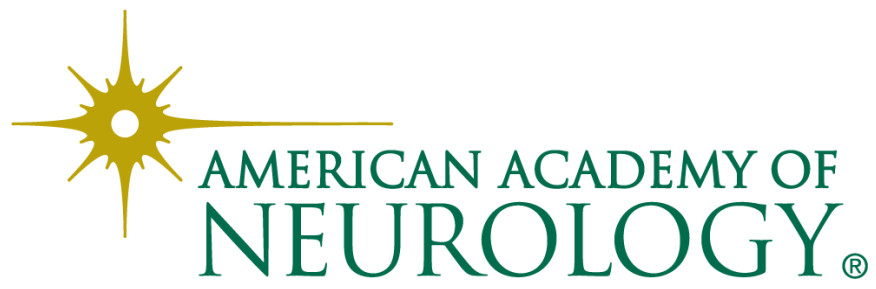

